\title{
International Journal of Clinical \& Medical Imaging
}

\section{Case Blog}

\section{Title: Abdominal Trompe-L'oeil Spirals}

Fasci-Spurio F, Serafini F, Zancanaro A and Presotto F*

Unit of Internal Medicine, Hospital dell'Angelo, Mestre-Venice, Italy
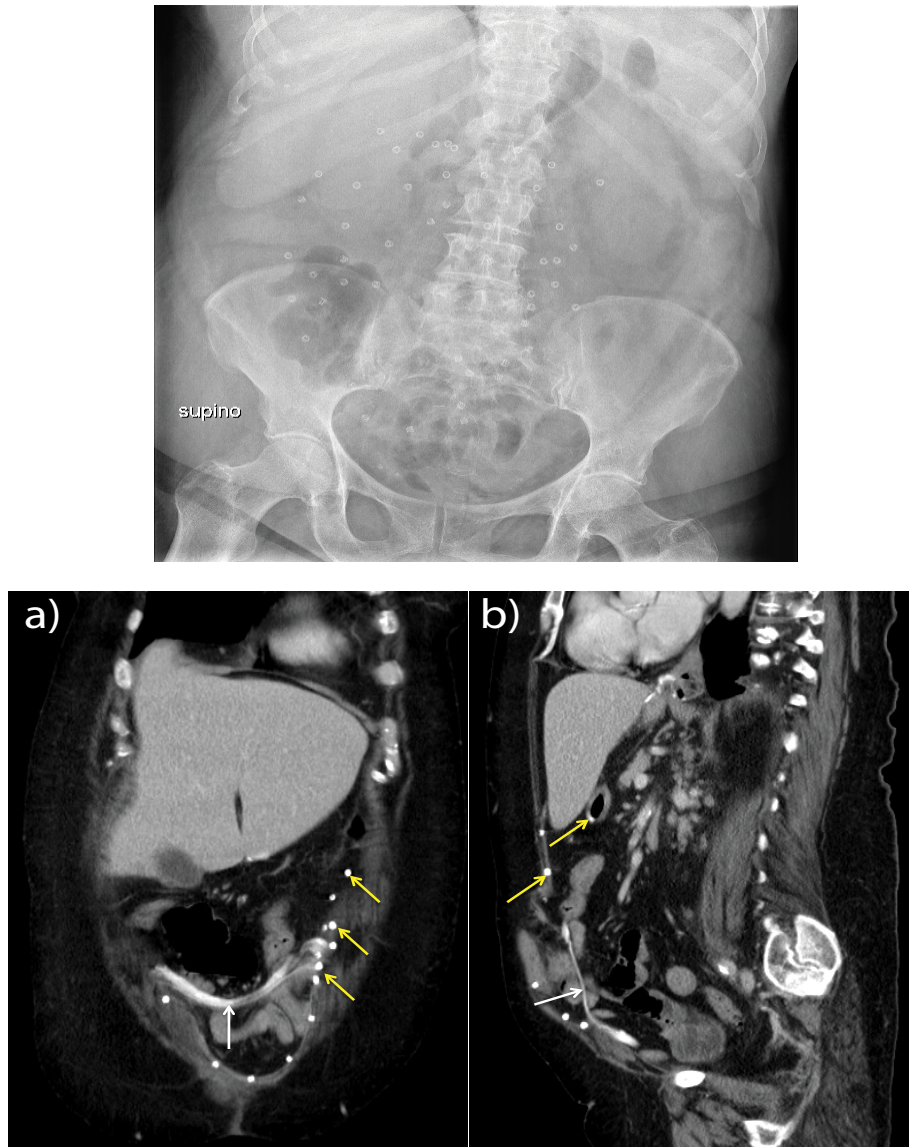

Figure 1: Abdominal anteroposterior plain radiograph showing multiple spiral-shaped radiopaque metal bodies.

Figure 2: Abdominal coronal (a) and sagittal (b) computed tomography cross sections showing a mesh in the abdominal wall (white arrows) and multiple coiled radiopaque metal autosuture tackers (yellow arrows)

\section{Case Blog}

A 69-year-old woman arrived to our Department for abdominal pain, hyperpyrexia and acute confusional state. Patient's history was remarkable for bipolar syndrome, severe binge eating disorder with morbid obesity. In 2009 she underwent to bariatric surgery followed by $57 \mathrm{~kg}$ weight lost, from initial $142 \mathrm{~kg}$. Height was $160 \mathrm{~cm}$. Because of a wide laparocele, in $2010 \mathrm{she}$ underwent to unspecified surgical repair. She was daily taking valproic acid $1.000 \mathrm{mg}$, fluoxetine $20 \mathrm{mg}$, and alparazolam $0.50 \mathrm{mg}$. Physical examination showed diffuse abdominal tenderness, high fever, and macrohaematuria. Neurologically she was somnolent and confused, condition ascribed to fever $\left(39.3^{\circ} \mathrm{C}\right)$ or possible inappropriate assumption of psychoactive drugs. A plain film of the abdomen in anteroposterior projection showed multiple radiopaque spiral bodies (Figure 1).

\section{Discussion}

The initial suspicion was foreign metallic bodies ingestion (clothespins) in a psychiatric patient with binge eating disorder. However, abdominal computed tomography described radiopaque devices consistent with a mesh and metallic spirals detectable in herniated bowels. No intestinal perforation or obstruction was found (Figure 2). It was then clear that the foreign bodies were

*Corresponding author: Presotto F, Unit of Internal Medicine, Hospital dell'Angelo, Mestre-Venice, Italy; Tel: +39(0)41-9657346; Fax: +39(0)419657353;

E-mail:fabio.presotto@ulss12.ve.it
Copyright: (C) 2016 Fasci-Spurio F, et al. This is an open-access article distributed under the terms of the Creative Commons Attribution License, which permits unrestricted use, distribution, and reproduction in any medium, provided the original author and source are credited. 
spiral tacks employed for intraperitoneal mesh fixation by laparocele repair operation. Different fixation devices can be incidentally observed on plain abdominal radiographs. Materials from which mesh is manufactured are usually derived from polypropylene and functions as a bridge across defective tissues. The mesh is usually located in preperitoneal layers and held in place with tissue glue or metallic tacks [1]. Length of tackers is about $5 \mathrm{~mm}$. They occasionally penetrate the neighboring structures, migrate into the peritoneal cavity and induce bowel perforation due to their sharp plug components [2,3]. If not carefully fixed, tackers can fall into the abdominal cavity or the sharp end of a tacker not buried properly cause injuries with movements. The patient had a final diagnosis of pyelonephritis and she was successfully treated with a course of intravenous ciprofoxacin.

\section{References}

1. Jamadar DA, Jacobson JA, Girish G, Balin J, Brandon CJ, et al. (2008) Abdominal wall hernia mesh repair: sonography of mesh and common complications. J Ultrasound Med 27: 907-917.

2. Haltmeier T, Groebli Y (2013) Small bowel lesion due to spiral tacks after laparoscopic intraperitoneal onlay mesh repair for incisional hernia. International J Surgery Case Reports 4: 283-285.

3. Golash V (2008) Large gut fistula due to a protruding spiral tacker after laparoscopic repair of a ventral hernia. Oman Medical Journal $23: 50-52$. 